A77

UNAM

|||||||||||||||||||||||||||||||||||||||||

21057

INSTITUTO DE GEOLOGIA - CU 
s-du

200511529 



\section{EL OLIVO}

SU

\section{CLLTIVO, INDTSTRLA Y COMERCIO EN LA REPUBLICA MEXIGANA}

POR

JOSE G. VAZQUEZ

Agricultor-Industrial

en Ayotla. Estado de México.

SFGUIDO DE UN ESTUDIO MEDICO

POR YL DOCTOR

\section{GUHLERMO TELLEZ}

\section{MÉXICO}

OFIC. TIP. DE LA SECRETARIA DE FOMENTO

Calle de Ban Auäres, número 15.

$$
1898
$$





\section{EI O L I V .}

SU AGRICULTURA, INDUSTRIA Y COMERCIO.

\section{INTRODUCCIÓN.}

El olivo, esa planta testigo mudo de los tiempos, que ha visto suceder todas las generaciones que han poblado y pueblan la vasta región del Anahuac, desde la tenebrosa Era de los tiempos primitivos hasta la actual generación, que le contempla hoy bajo el majestuoso $\mathbf{y}$ grave aspecto que le admiraran los primeros hombres de la tierra, no es, como creen algunos autores, un vegetal aclimatado en nuestro suelo; él vino á nosotros con el secular encino, el clásico agave y otros millares de especies cuya cuna era ignota; desde la última transición del planeta, con los demás gérmenes esparcidos sobre el liaz de la superficie terráquea; de aquesa costra primitiva que, según el sabio Pelletan, formó después el Nuevo Continente al ocupar en su desplazamiento el lugar asignado siglos después por Newton en su ley de gravedad.

Su origen, á juzgar por la denominación mexicana, 
Chinquauhcapolli, que se conserva entre nosotros, nos demuestra, que era conocido desde los primeros tiempos en el snelo azteca, y no como juzgan algunos que fué importado por los españolcs. El progresa en varias regiones de América, centro del Asia y fué introducido su cultivo en Europa por los Phocenos cn la época en que éstos fueron á establccer su colonia en Provenza y hoy constituye una de las fuentes de riqueza para las regiones meridionales de la Europa. Entre nosotros, vegeta con predilección en los Estados de México, esencialmente en el Valle, á los alrededo. res de la capital; en Guanajuato, Durango, Tlaxcala y la Baja California. Su mayor cultivo é industria aceitera la tiene en el Estado de Guanajuato, en donde la estadística hace subir su producto anualmente á la cifra de 7,000 arrobas de aceite. La importación de este precioso vegetal, fué sabiamente comprendida hace algunos años por el genio iniciativo del Ministro de Fomento, Sr. General D. Carlos Pacheco, que hizotraer á la República cincuenta mil estacas de olivo de la Provincia de Andalucía en España, de las variadas especies que se cultivan para su propagación y que des. graciadamente no se utilizaron al objeto de su propósito por circunstancias que no nos ha sido dado conocer; acaso, nuestro clima no es propio á su aclimatación, al menos en los lugares donde se implantaron, pucs por mi parte los que recibí con tal objeto no tuvieron resultado. 
AGRICULTURA.

Especies de terrenos, situación topográfica y condiciones climatéricas.

Los terrenos para el cultivo del olivo difieren entre sí, según hemos podido observar, en ellos vegetan las tres variedades que conocemos y de que se habla más adelante; así pues, tratándose de la del fruto grande que se conoce con el nombre de aceituna gorda ó gordal, y que se emplea en lo general para encurtidos, los terrenos en que vemos progresar esta especie, son aquellos que situados en los llanos están compues!os en lo general de tierra gruesa, llamada vulgarmente de migajon, y sus mejores condiciones de poseer surtidores de agua, hacen propicio el riego equilibrando los dos extremos de temperatura con un moderado calor. No así los terrenos situados en puntos más elevados que las dichas planicies que requiere la anterior especie, ellos se hallan situados en las faldas de grandes 6 pequeñas eminencias de montañas ó colinas y son los más propicios para la especie conocida con el nombre de Manzanilla, impropiamente entre nosotros denominada así por algunos científicos que han tratado de especificar nuestras variedades comparativamente con las especies españolas, que están muy lejos de ofrecer la misma identidad. Sea pues la especie de aceituna manzanilla, conocida entre nosotros con el nombre vulgar de aceituna redonda, para la cual convienen mejor' 
dichos terrenos, que acusan una temperatura fría y templada de donde procede la variedad del fruto: estos requieren una tierra más delgada y arenosa. Su situación topográfica sería un inconveniente para éste y otros muchos vegetales, siendo así que las aguas tem. porales que se precipitan de las alturas, las más veces torrenciales, son causa de frecuentes deslaves que tienen lugar en las faldas de los cerros ó colinas, y llegan á descubrir las raíces de los árboles implantados en sus bases, lo cual, si no so tuviera la precaución de amontonarles tierra al pie de ellos, como se verifica, no se lograría su vegetación. Esta circunstancia, que bien puede presentarse en otra especie vegetal sin perjuicio alguno, en el olivo no procede de la misma manera, por ser un árbol cuya raíz profundiza poco el suelo en que vire, y terminaría por desarraigarlo, como lo hemos visto prácticamente los que estamos dedicados á su cultivo, á cuyo propósito, repito, hay que cubrir el tronco hasta la altura de 90 á 100 centímetros con tierra para resguardarlo tanto de las lluvias torrenciales como de los huracanes.

En términos generales diremos, que los terrenos requeridos por el olivo, son los que están dotados de los elementos más substanciosos, aunque el subsuelo sea de naturaleza arcillosa, de cascajo, pedregal ó arena, pero siempre con algo de migajón.

Esto, por lo que respecta á la calidad del terreno; pero por cuanto á los elementos atmosféricos, es indispensable que los plantíos en terrenos fríos estén resguardados de los vientos nortes para evitar la mayor influencia de los fríos arrasantes del invierno. 
Teniendo en cuenta las condiciones favorables bajo las cuales vegeta el olivo, ya sean las adquiridas por nuestra propia experiencia, como por la práctica extranjera, respectivamente á la especie que es objeto de un esmerado cultivo en los terrenos fríos de la nevada Andalucía y los que vemos crecer entre nosotros en tierras cálidas como templadas, podemos sentar como un principio: que el olivo soporta las temperaturas frías y calientes, á juzgar por las especies que vegetan bajo la influencia de ambos temperamentos; pero que lo mismo el extremado frío, que el demasiado calor le son perjudiciales. Aquel influye poderosamente en contra de la planta cuando ésta se halla en su tierna edad, hasta los tres años, y bajo la influencia de un extremado calor la planta llega á ser estéril. Así, el cultivo en ambas temperaturas difiere entre sí, siendo objeto de las diferentes variedades que se observan en la especie, habiéndose clasificado ya hasta diez.

Los terrenos se preparan como para cualquiera otra planta, dando labores para la extirpación de hierbas adventicias y riegos que estén en relación con la necesidad que reclamen, sin exceder de una humedad media, á fin de evitar la demasiada, que perjudicaría á las raicecillas una vez hecha la siembra.

\section{MULTIPLICACIÓN.}

El olivo se propaga de tres maneras diferentes, esto es, por semilla, guía y estaca. La primera es la menos adoptada entre nuestros cultivadores, la segunda aun- 
que más tardía tiene algún uso, y la última es la más generalizada.

La propagación por scmilla se hace por medio del hueso de la aceituna, la que cs incicrta en su producido, y para prepararla á su plantación se dejará en agua durante 48 horas, al fin de las cuales se siembran de dos en dos semillas, distantes cntre sí un metro, cubriéndolas en seguida con una capa de tierra suelta de 6 ú 8 centímetros de cspesor y colocadas en línea recta distantes un metro interlineal. La sicmbra debe verificarse en climas cálidos en cl otoño, en los templados, calientes y fríos de Enero á Junio; al comcnzar á brotar las plantas destinadas á su lugar debe evitarse la influencia de los rayos solares, cubriéndolas con zacate seco en forma de embudo, durante un año. La propagación por este medio es desusada por la dilación con que fructifica, aunque hay opiniones de que su duración es máxima á la de los otros medios empleados, lo cual es difícil do comprobar por ser un vegetal de vida muy larga. Mas lo que nosotros podemos asentar por la experiencia que tenemos es, que este medio es el más ineficaz y que la especie degenera hasta la desaparición completa del fruto.

La propagación por gicía se verifica con el producto de la poda que tiene lugar á los ocho años de plantadas las estacas, con la diferencia que los espacios que separen una de otra planta son menores que en los de la precedente. Por este medio de propagación se obtienen mayor número de plantas en menor extensión de terreno; pero el fruto es menos abundante en razón á que estando más próximas, llegan á entrelazarse las 
ramas disminuyendo la ventilación de la planta, lo cual impide la fructificación, por cuyo inconveniente no nos detendremos en inás detalles. Por otra parte, su propagación por este medio está sujeta á las prescripciones observadas en la precedente.

Para obtener la propagación del olivo por estaca, que es el medio más generalmente adoptado entre nuestros cultivadores, se verifica por almácigas en cepas de 80 á 100 centímetros de largo por 30 centímetros de anclio y 50 de profundidad, poniéndose al efecto las estacas en agua por espacio de 24 horas, teniendo una longitud de 50 centímetros, y se colocarán de dos en dos en cada cepa, longitudinalmente, como se practica con la caña de azúcar, en liileras distantes entre sí 16 centímetros. Se cubren de tierra á la altura de otros tantos centímetros, pues si excedo de esta porción la planta no se desarrolla.

Al verificar el plantío con dos estacas en una misma cepa, es con el fin de aprovechar una de ellas, dado caso que la otra se pierda del almácigo, en donde deben permanecer un año para su trasplante.

\section{TRASPLANTE.}

Una vez determinado el terreno sobre que se ha de verificar el trasplante, llenando las condiciones prescritas, las cepas deben estar preparadas de antemano, á fin de que reciban el primer abono en que la pródiga naturaleza beneficia la tierra del cultivo por medio de sus meteoros, tanto más, si esta es arcillosa, cascajosa 
ó bien gredosa. Los espacios que deben mediar de una á otra cepa en el plantio permanente, serán de 20 metros, y el tiempo oportuno para verificarlo, en la luna creciente de Enero ó Julio. Al efecto se coloca la planta en el centro de la cepa repartiendo cuidadosamente sus raíces por igual, y cubriéndolas poco á poco con la mejor tierra que se haya destinado; la mezclada con los despojos de encino y perú son lis inás propicias para el objeto, interceptando la última capa con un abono de estiércol, bien podrido, de ganado cabrio.

La especie de olivo que se propaga, influye también para determinar la distancia que inedie entre una y otra cepa, en razón de la mayor 6 menor corpulencia con que cada una de ellas se caracteriza; así, la acsituna redonda y gorda requiere menor distancia que las otras dos; en éstas deben estar colocadas las cepas á 12 metros, mientras que las otras á 20 , sin las condiciones de otro sistema que en seguida se dirá y sólo á ésta se cuidará de quitarle los retoños que salgan al pie de la planta.

El segundo sistema de plantación es á 10 metros de distancia de una á otra sólo de aceituna delgarla para formar los arbustos, comenzando su poda á los 150 20 años, ó bien cuando se advierta se una el follaje con las plantas contiguas, y cada cuatro años se podarán sus guías cuidando que estén libres las plantas de una á la otra; y el plantío de 20 metros sólo se aseará la planta en quitarles las ramas secas y los retoños que salgan al pie de la planta en su primera edad. 
PODA.

Sin embargo de estar bien consideradas las distancias que deben separar las plantas que pueblen un olivar, consideradas liasta en el particular que cada una de Jas especies requiere para no oponer obstáculo á todo su desarrollo, el olivo, más que alguna otra planta, necesita de este esencial beneficio; sus largas y espaciosas guías llegan á entrelazarse unas con otras, al grado de interceptar los rayos de la luz solar, influyendo lo bastante para esterilizar su fructificación al cabo del tiempo, si no se tiene el cuidado de cortar algunas ramas que de otra manera privarían la ventilación. No menos esencial es esta práctica respecto á los renuevos que tienen su origen en las raíces del árbol: para verificarlo tiénese en cuenta la época más conveniente; ésta debe fijarse siempre antes del invierno, esto es, al terminar el otoño, ó después del rigor de la estación fría, procurando que las lesiones que deja el instrumento de poda sean cubiertas del aire con excremento de vaca ó con lodo, como generalmente se emplea, á fin de evitar las heridas. Se lıa fijado por algunos autorés, que la poda del olivo debe hacerse cada dos años; pero este tiempo no puede ser limitado para todos, y lo más conveniente es la que reclame cada árbol según su mayor ó menor desarrollo. Sí es muy esencial," sentar como principio, la ventaja de hacerla especialmente sobre la cúspide del árbol á fin de disminuir la altura colosal que llegan á obtener, con el objeto de facilitarle la fructificación, hacerla más productiva y menos laboriosa su recolección. En estas 
circunstancias el árbol gana en volumen lo que pierde en longitud, tanto más, cuanto que está demostrado por la experiencia que el fruto más alto es el que menos se logra, pues muchas veces no llega á madurar.

\section{RIEGO.}

El riego difiere también en las especies: en los climas fríos debe procurarse á la tierra una lumedad suficiente en los primeros cinco años del nacimiento de la planta. La cantidad de agua hemos podido valorizarla de 20 á 25 litros por semana. En los templados de 18 á 20 litros cada tercer día, y un poco más en los calientes.

DESARROLLO PROGRESIVO DE LA PLANTA.

Una veż hecha la propagación del olivo por medio de estacas según las prescripciones indicadas anteriormente, ésta, implantada definitivamente en el lugar do su permanencia brotan sus raicecillas al año y su progreso es paulatino, influyendo bastante el clima en donde se cultiva; pero pudiendo determinar en lo general el tiempo requerido para que brote la guia en un período de 4 á 8 meses, que está en relación con el espesor de la capa de tierra que cubre la estaca y que en lo general brota por la parte extrema, alcanzando su desarrollo medio á los cinco ó seis años, en cuyo período la planta requiere todo el esmerado cuidado indi- 
cado al tratar del riego y poda, hasta los cinco años en que se determina con certeza la especie propagada, pues antes de dicho período, la estructura física del olivo no ofrece carácter especial de variedad, y pasados los 6 alfos son dos aspectos los que representan, una, la superficie lisa que se observa en la especie de aceituna delgada, y la otra que, por el contrario, se manifiesta estriada, con protuberancias rugosas en toda su extensión, que es el carácter que distingue á la aceituna gorda de la delgada y que algunos han atribuído á la falta de cultivo y que no es debido sino á la especie.

La fructificación tiene lugar partiendo de aquella época hasta los 30 ó 50 años en que se adquiere una gran corpulencia, y en cuyo tiempo ha llegado á producir un árbol hasta 60 arrobas de aceituna, esto es en las plantadas á 20 metros, y las de 10 su producido es de 30 á 40 arrobas, conservando estas últimas su producción igual por año, y las de 20 metros su producido hasta 100 arrobas á 100 años.

Una vez dotada la planta de los cuidados que exige de la mano del hombre en un período de seis años, se abandona á sí misma y al solo cuidado de la naturaleza que le da todos los elementos requeridos en su duración, hasta una época avanzada que no es dable al hombre seguirla en su marcha progresiva, pues su vida se pierde en la inmensidad de los tiempos, siendo testigo mudo de los diversos acontecimientos de los pueblos y sus generaciones. 


\section{RECOLECCIÓN DEL FRUTO.}

La recolección de la aceituna tiene lugar en Septiembre y Octubre, y se hace de tres maneras diferentes, á saber: á mano por vara y por sacudimiento. Las tres son bien conocidas para dar una explicación superffua, y sólo indicaremos que el primero de estos medios es el inás conveniente y por ol cual el fruto no sufre, lo mismo que las ramas, ningún deterioro, pudiendo resumir en 4 las condiciones requeridas al objeto:

1? No obstante la época fijada para la cosecha, como no todos los frutos madnran á la vez, éstos deben cosecharse á medida que vayal sazonancio.

2? Al verificarlo el medio indicado es á mano.

3? Depositar el fruto ya cosechado en un lugar seco á la vez que ventilado, evitándule la humedad y el frín, y

4: Que no exceda su reposo del tiempo necesario para la extracción del aceite ó su conservación.

En la Sección de Industria se previene lo conducente.

\section{ENFERM EDADES.}

El olivo, como todos los individuos que comprende el reino vegetal, es susceptible de contraer enfermedades como todo sér organizado de la naturaleza, una vez alteradas las condiciones normales de su existencia, hasta su destrucción completa, á virtud de las causas morbosas que rodean al común de las especies y que 
se oponen á su natural desarrollo. Así, no es raro ver en este individuo vegetal, la palidez que se advierte en lo general en Jas plantas enfermas, un raquítico crecimiento, la escasa ó nula influrescencia y, con ello, hasta la abulición completa del fruto, que, fuera del común de aninales dañinos que le perjudican, los nuevos seres, los vegetales queá sus expensas tienen vida y crecimien. to, se oponen á su natural desarrollo, tales como las plantas parásitas, y en fur, la multitud de otras causas externas que tienen su origen en los mismos elementos físicos que los rodean y soll otros tantos enemigus que conspiran contra su existencia.

La patología yegetal sin embargo de los progresos alcanzados hasta el día, no ha llegado aún á valorizar en lo general de las especies vegetales, el particular de sus afecciones morbosas que le son propias á cada uno de los individuos que pueblan este inmenso reino de la naturaleza; sin embargo, por analogía con el de las especies animales, admitimos un estado anémico en lo general, semejanteal de las razas humanas, que simulan una palidez pigmentaria, caracterizando una ligera modificación en la sangre de los animales que nutren sus tejidos, como en la savia de los vegetales, á virtud de cuyo elemento indispensable tienen vida, $\mathrm{y}$ no podemos menos que declarar un estado morboso, encontrando tanta analogía en el común de las especies vivientes, que vemos, por ejemplo, que el fierro empleads como elemento terapéutico en las especies animales con el objeto de dutar á la sangre de la cantidad de glóbulos rojos á cuya falta se empobrece, ser compatible para remediar las alteraciones del vegetal, 
que simulan en su modo de ser, un estado semejante en su decoloración al que pintan la faz del individuo enfermo: habiéndose obtenido por medio de irrigaciones ferruginosas con el hierro hidratado, el cambio simultáneo de esa palidez mortal que se advierte en las hojas de muchas plantas enfermas y la restitución de su natural color.

Estamos, pues, dispensados de hablar nosográficamente respecto á las alteraciones mosbosas de esta planta, como del común de las especies vegetales, por hallarse aún en cuna la patología vegetal, y sólo haré referencia de las que el vulgo nos da á conoceo en su eficaz observación y no menos eficaces medios para remediarlas.

Aludiendo á ese síntoma morboso tan general en casi todas las plantas que adolecen algún mal y que interpretamos nosotros un estado anémico: al comenzar á palidecer el color verde de las linjas, cambiante al fin en amarillo, acostumbran los cultivadores excavar la circunferencia del tallo arbóreo en la tierra hasta descubrir algunas raíces y abonar con nueva tierra compuesta con estiércol de ganado vacuno y lanar, haciendo la base de ese abono los despojos de algunos vegetales, particularmente los del encino, cubriéndose con ella toda la superficie excavada y la última capa con tierra vegetal nueva, regando en seguida y reservando la tierra extraída por la excavación para cubrir después la parte inferior del tallo dándole así más fuerza.

El olivo, no obstante ser un vegetal de larga vida, pudiera concedérsele la mayor solidez de que disfrutan otras plantas seculares quo están provistas de largas 
y espaciosas raíces que las aseguran en la tierra, no es̃ así, sus cortas raíces hacen indis pensable dotarle mayor fuerza para que resista los vientos cúya pujanza no podría contrarrestar; por eso se practica rutinariamente entre nosotros desde nuestros antepasados, proveerlo de una doble base de tierra para poder resistir la fuerza de los vientos, á cuyo objeto ya recomendamos en la sección anterior, sean implantados al abrigo de los nortes; por ello vemos realizarse su mayor estabilidad en aquellos lugares guarecidos por una alta muralla, como se hallan en lo general en las huertas de los alrededores de México.

La anterior prescripción, como todas las que tiendan á remediar el común de las enfermedades de este vegetal, deben verificarse en el invierno, según lo demuestra la práctica con sus buenos resultados.

Se ha indicado como panacea de las enfermedades del olivo, cuando se advierte su decrecimiento rápido, desconocido en su causa, la excavación de la tierra en circunferencia hasta llegar á las raíces y poner en contacto de ellas la cantidad de 36 litros, 6 sean los residuos del fruto que se somete al molino para la extracción del aceite, agua mezclada con bagazo, si se trata de un árbol grande, ó la mitad para arbustos, adrirtiendo que no contengan porción alguna de sal, porque está demostrado que esta substancia todo lo que tiene de benéfica para la conservación del fruto en salmuera, tiene de nocivo para su cultivo.

Si el vegetal es atacado de carcomas y resequedades en su base, se destruyen estas partes malsanas ó muertas, con un cuchillo, reemplazando las oquedades que 
dejan sus despojos con una parte de barro mezclada á otra de bagazo de aceituna.

Si el árbol fuese atacalo de algín mal comenzando por sus guías que se adviertan secarse, se amputa la parte enferma y en último caso la mayor partedel tallo ó hasta un metro á pelo de tierra para lograr cuan. do menos la sucesión por el retoño.

En fin, cuando sin causa conocila se desarrolla el árbol sin producir fruto, se amputa dos metros arriba del suelo en que vegeta, abonándole por inedio de ex. cavación con las 'materias excrementicias animales y despojos vegetales que hemos detallado antes, $\mathbf{y}$ cuyo remedio á su fructificación tenemos indicado también en la sección agrícola.

Si el árbol es estéril, se consigue también hacerlo fructificar aplicándole un barreno á la raíz principal; algunns lo verifican en la parte inás baja del tallo, aun para los que no carecen completamente de fruto, introduciéndole una estaca, que también prefieren que sea de madera de ocote, en el punto perforado, abonán. dose con estiércol de cabra, podrido, puesto al contacto con las raíces.

La esterilidad del árbol también es por causa de lıumedad permanente; ésta se nulifica por medio de la cal opagada, aplicada hacia el interior de la excavación que se practica al pie sin llegar á la raíz, cubriéndose la oquedad con tierra nueva bien seca. En caso contrario, la excesiva resequedad de la tierra tiende también á contrariar el perfecto desarrollo del olivo, y es contado en el número de los enemigos, ya climatulócicicos, ya á los que pertenecen más exclusivamente á la im- 
propiedad del terreno en que vegeta; sin embargo, puede presentarso este inconveniente como causa accidental, y entonces obsérvase en las ramas, en su tierna edacl, nudosidades que se remedian cuando proceden de pobreza de los elementos químicos-nutritivos con que clebe estar dotada la tierra, amputando algunas de las raíces que se descubren al objeto por medio de excavaciones, reemplazando la tierra extraída por otra más análoga, nueva, gruesa, y si fuese posible, procedente de encinos, abonándola con estiércol y cuidando de darle la suficiente humedad por medio de riegos que no excedan de lo regular.

Hemos tratado de las alteraciones del olivo bajo el imperio de ciertas causas que obran en contra de su desarrollo, réstanos a hora consignar aquí entre las otras plagas que asedian á los vegetales los parásitos, de que no se hallan exentos ninguno de los seres del reino vegetal.

El olivo da vida como otros muchos vegetales á algunas especies de lamas, musgos, etc., cuéntảse entre éstos esencialmente el pastle con que suelen verse invadidos sus tallos, siendo tan conocidos los efectos esterilizantes de las plantas á cuyos auspicios viven estos seres inferiores, que es por demás recomendar su extirpación.

Finalmente, es de recomendarse la profilaxia en ge. neral, pues de la misma manera que se evitan las enfermedades del cuerpo animal, se pueden evitar las que son susceptibles de atacar al organismo vegetal.

Para precaver al olivo de las enfermedades que lo atacan, deberán prodigársele desde su tierna edad irri-

El olivo,-2 
gaciones directas por medio do jeringas ó bombas que impulsen con fuerza el agua contenida en los pistones, en la forma de menuda lluvia, desde la cúspide hasta el tronco, para desalojar las materias extrañas que se adhieren, tales como insectos, tiorra, materias putrescibles, tanto animales como vegetales, y aun de sus propios despojos reducidos ci tierra vegetal que se opo. nen á la libre transpinción de sus hojas, que absorben el carbono del aire, y que en su defecto darán abrigo indudablemente á esos nuevos seres de las especies parásitas á que aludimos, y que viviendo en el olivo ocasionan en último resultado su enfermedad, para evitar en gran parte abrigo de varios insectos se aplicará á las ramas gordales hasta el pie, baños de agua do cal consiguiendo con este baño fortalecer dicha planta, y la operación se hará cada dos años.

\section{II}

INDUSTRIA.

Extracción del aceite.-La extracción del aceite de olivas se obtiene de dos maneras diferentes: por presión en frío, ó bien por calefacción con el fruto verde ó en perfecta madurez. En el primer caso se mantiene en asoleaderos para conseguir la evaporación del agua que contiene, lo que se verifica al cabo de 30 dírs, quedando el fruto enjuto ó cliupado, en cuyo estado se somete al molino; lo que flota en la superficie del líquido 
es el aceite puro que resulta de la aceituna. El aceite de olivas ó aceitunas fermentadas no se extrae hasta haber destruído una parte de las materias vegetales por la fermentación; este es el aceite de peor calidad, pues que conserva un gusto desagradable y se arrancia muy fácilmente. Una vez extraído el aceite, se le agrega una pequeña porción de sal marina que absorbe el agua que contiene y permanece, al decantarlo, en el fondo del receptáculo en solución saturaủa, quedando por esta vía clarificado y en estado de conservación.

Conservación del fruto.-Se pone á desflemar la aceituna en agua común por espacio de quince días, renovándola cada tercel día, al fin de cuyo tiempo se habrá desacidulado, y entonces se le mezcla uno y medio cuartillos de sal marina, cuatro cabezas de ajo descortezadas, diez limones sajados, tomillo, mejorana y doce onzas de orégano, y al cabo de quince días que se conserva en un barril de ochenta litios, conteniendo cincuenta kilogramos del fruto de aceituna delgada, quedará preparado en salmuera y su duración será de un año. La aceituna gorda morada se prepara de la mis. ma manera, con excepción del tiempo que se tiene en maceración, y que está limitado á cuatro días, desechando al objeto todo el fruto que esté pasado de madurez, pues así su duración es máxima. La preparación de la aceituna gorda verde, se verifica de la misma manera, y su duración excede de 20 años. Hay otra variedad gordo-morada, que se prepara sajándola con 4 incisiones longitudinales y que dura un año conservada, pudiéndola comer al mes de preparada.

Usos._El aceite superior de la aceituna, se emplea: 
en la relojería, para facilitar el movimiento de su delicada máquina de precisión; en Ias maquinarias, aparatos é instrumentos, para dulcificar su movimiento; en los instrumentos de cuerda, para friccionar éstas, dándoles la transparencia que obtienen y son conocidas entre los filarmónicos con el nombre de cuerdas de tripa.

Unido á la cera, forma el serato medicinal y otros ungüentos que se preparan en las oficinas de farmacia.

En la economía doméstica tiene grande aplicación para condimentar muchos guisos, siendo también la base de las ensaladas y escabeches.

En fin, en la industria jabonera se emplea en la fabricación de los jabones de primera calidad, y en otros muchos casos que omitimos enunciar por no ser muy difusos sobre el particular.

Falsificación del aceite de olivas.-Sienclo el aceite de olivas de más valor que los otros procedentes de algunas semillas, como la de los claveles, nabo, etc., para reconocer esa falsificación, se trata por el nitrato ácido de mercurio que coagula el aceite de la aceituna, dejando líquidos los demás.

Rousseau indicó otro medio que consiste en interceptar el hilo conductor de una pila voltaica muy débil por una pequeña taza llena de aceite y ensayar la conductibilidad de este líquido por la desviación de una aguja imanada: el aceite de aceituna puro, es poco conductor de la electricidad, mientras que todos aquellos que provienen de otras semillas son buenos conductores.

La e ebanistería en los cortos ejemplares que han lle- 
gado á nuestra vista, nos ha mostrado las bellas obras de pulimento de que es susceptible, en su aprovecha= miento, la albura del olivo.

Su estructura es compacta, de una dureza extrema que está en relación con su mayor edad, y exhala un suave olor sui generis. Podría substituir al caobo; sus bellos matices a marillos y negros hermosean los artefactos de la mano del hombre; pero se dice que el bar. niz se desprende con facilidad al poco tiempo de empleado; esto sería un inconveniente grave, en efecto, si no existiese un material más adherente, que no dudo lo habrá, pero en su defecto no sería difícil adquirirlo por algún otro procedimiento especial que no sea de los conocidos. Su dureza y compatibilidad, repito, le dan la preferencia á las otras maderas que emplea el arte, especialmente en la construcción de cierta clase de instrumentos de música que requieren esas condiciones.

\section{III}

COMERCIO.

La reducida zona agrícola del olivo en el país hace tan exiguo tráfico de este fruto, que no permite mayor comercio que la corta demanda de las pequeñas poblaciones donde es objeto del cultivo; más como esta planta está llamada, como otras muchas de nuestra magnífica flora, á hacer gran papel desde el triple aspecto agronómico, industrial y comercial, comenzaremos por 
dar una ligera idea respecto al costo de su corto beneficio; dato que es indispensable bajo el punto de vista comercial, en que debe fundarse el comerciante de cualquier producto que se consigna al mercado, tanto interior como exterior de nuestras producciones.

La extensión de terreno que exige el plantío de un olivar está en razón de 400 plantas por fanega de sem. bradura; así, en mayor escala está calculado, para una caballería de tierra, 4,800. El precio del terreno es muy variable, tanto como lo son las diversas condiciones que ellos guardan respectivamente entre sí; mas puede valer próximamente á 300 pesos por fanega.

La planta de 24 centímetros vale 18 centavos. Cada peón planta de 30 á 40 estacas diariamente, y el gasto erogado se estimará en un peso por cada planta hasta 150 años de plantada, no exigiendo en lo sucesivo la referida planta on su desarrollo, más que un pequeño aseo y blanqueando las ramas como antes se ha dicho.

Hemos dicho que el riego debe hacerse en los primeros cinco años que constituyen el total beneficio de la planta; pues después de este tiempo se abandona á sí misma, y nos parece del caso precisar que la irrigación no debe ser más que artificialmente con exclusión de aguas riviales que únicamente pueden ser empleadas después del tiempo prefijado al riego de mano en la forma y condiciones prescritas en la sección relativa.

La constante humedad de que debe estar provista la planta influye en su mayor progreso, y con ello en la mayor producción.

De las tres especies ó variedades indicadas de este 
fruto, la aceituna delgada es la destinada para la extracción del aceite; las otras son más propias para su conservación en salmuera.

El costo del aceite extraído del fruto verde de la aceituna, en buena cosecha, es de 1 peso 50 centavos por arroba mandándola maquilar, y cuando esta operación es por cuenta del industrial, es de 1 peso á 1 peso 25 centavos, correspondiendo á este valor 50 centavos del corte y 75 centavos de extracción. En las malas cosechas, el costo es mayor: de 1 peso 40 centavos á 1 peso 80 centavos, según que se maquila por cuenta propia ó extraña; 30 arrobas de fruto verde de - aceituna, ó sea una parada, producen de 5 á 6 arrobas de aceite.

El precio del aceite es de 5 á 8 pesos la arroba, que consta de 22 libras, que embotelladas equivalen á 8 litros próximamente, siendo susceptible de alza este precio cuando hay escasez del producto. Al por menor el precio de una botella de 3 de litro es de 62 á 75 centavos, lo mismo que el aceite extranjero, que no obstante su clasificación y mejor calidad que se le concede, carece del suave olor y mayor cuerpo que da el extraído en nuestras fábricas.

El precio que guarda la aceituna conservada es de 8 á 10 pesos barril, y al por menor 25 centavos cuartillo de granos; fruto revuelto y escogido, envasado en frascos de cristal y en número de 60 aceitunas, á razón de 50 centavos el frasco, $y$ son conocidas en el comercio con el nsmbre de aceituna reina. 


\section{CHIQUAUHCAPOLLI.}

Pl. núm. 423.-2a serie Flora Indígena.-Dr. Gmo. Téllez. (Apuntes para la Farmacología mexicana.)

\section{SINONIMIA:}

Francés: Olivier (ol árbol).

Inglés: Olive tree.

Español: Olivo, el árbol. Ateituna, el fruto. Olivar, el plantío de olipos.

Latin: Olea Europea (Linneo Sp. 11, Blackw. t. 199).

Oleum olivarum (el aeeite de olivas).

Olea Americana, Sp. nostra.

Historia.-El Chiquauhcapolli de los antiguos mexicas deriva su nombre de las palabras chichic amargo, quauhitt árbol y capollin capulín, esto es, árbol de capulín amargo, sin duda alguna por la semejanza que tiene nuestro común olivo con el cerezo de Indias, como le llamamos los españoles á nuestro vulgar capulin, por corrupción de capullín, y cuyo fruto es muy parecido á una de las especies más comunes del olivo que vegetan entre nosotros, diferenciándolo el sabor amargo que acusan en general los frutos de éste.

Nuestro olivo es un bello y corpulento árbol, de elegante porte, frondoso follaje y aspecto grave que crece en el suelo mexicano; su longevidad data de los pri- 
meros pobladores del Anahuac, pero su exiatencia remonta más allá: hacia la primera edad del mundo.

El olivo vegeta con profusión en el viejo continente, siendo objeto de un esmerado cultivo por la rica producción do su aceite, que alcanza tantos usos, ya en la economía como en los diversos géneros de industria á que se aplica, así como en la medicina. Se ha pretendido que una especie de él, el Olea fragans de Vahl, cou lá flor; los hijos del celeste imperio dan á su té el aroma particular que exhala y causa tanto placer á su bebida fuvorita, constituyendo el secreto de la excelente calidad con que está calificado el té chino.

Descripción y clasificación botánica.-El olivo es un corpulento árbol que adquiere dimensiones considerables; llega á medir una altura de 20 á 30 metros y una circunferencia de 4 á 5 , proyectando una sombra hasta de 100 metros. Está compuesto de hojas opuestas, persistentes, coriáceas, un poco convexas ó enrolladas, ovales, agudas, de un color verdi-blanco. Las flores son pequeñas, axilares en la parte superior de las ramas, ofreciendo cada una un caliz casi plano con cuatro dientes, una corola campanulácea, corta, cuyo lim. bo es de cuatro lóbulos ovales agudos. Los estambres son algo salientes. El ovario es globuloso con dos tabiques biovulados; el estilo es muy corto, el estigma rollizo, alargado, ligeramente bífido. El fruto es una drupa ovoide ó más ó menos esférica, según la varie. dad, de un color amoratado que al fin de su madurez viene á ser negro, más ó menos intenso; contiene en su interior una nuez que afecta la misma forma y ofrece un solo grano por el aborto consecutivo de otros tres El olivo. -3 
óvulos. El grano está compuesto de un tegumento delgado y rugoso en disposición venosa y de un endospermo carnoso que contiene un embrión central encorvado.

Por estos caracteres de organización el olivo ha sido comprendido en la familia de las Jazmineas, tribu de las Oleaceas, procedente de la clase de vegetales monopétalos de estambres hipogineos de Jussicu.

Variedades.-Estas las constituyen las diversas formas del fruto, distinguidas en lo vulgar con los nombres de accitumas delgada, gorda y redonda, que caracterizan las tres variedades que vegetin en este suelo. Difieren la delgarla de la gorda en el color de sus hojas, sus dimensiones y su estructura: én la primera son menores, de un verde más obscuro y lustroso y menos resistentes; en las segundas son más claras, mayores, más dobles y menos encorvadas. Lns tallos son diferentes hasta la edad de seis años en que las cortezas ofrecen alguna diferencia: en la aceitula delgada el tronco es liso y en la gorda estríado y con algunas protuberancias. Respecto á la variedad que ofrecen los frutos, se observa en la aceituna delgada que la drupa es esférica, simulando la apariencia de un verdadero capulín, ya en su forma como en su color, lo que le ha debido el nombre mexicano que lleva de capulín amargo; y en la gorda su forma es oval, más carnoza y el endospermo de un color amoratado.

Propiedades quimicas. - Líquido graso viscoso, suave al tacto, de color amarillo verdoso, 6 bien verde sólido; á $6^{\circ}-0^{\circ}$, deposita estearina en cantidad de 0,28 ; su peso específico es de 0,9153 á $25^{\circ}$, de un olor y sabor 
agradables; es menos corruptible que los demás aceites vegretales.

De las especies europea y africana, dicen algunos autores, que escurre un líquido gomo-resinoso de color moreno, en lágrimas ó masas más ó menos voluminosas, transparentes ú opacas, algunas veces reunidas en masa, y que, según el profesor Pelletier, está compuesto de una materia resinosa, una pequeña porción de ácido benzoico y de un principio particular, que este sabio químico denominó Olivila, que al presente es desusado en la terapéutica extranjera.

La Olivila es, pues, el principio activo del olivo, ex. traída de la goma-resina de las especies extranjeras, que se obtiene en cristales blancos y son solubles en el agua caliente.

Sinonimia: Español, Aceite de Olivas ó de Olivo; Aceite de comer. Francés, Huile d'Olive. Inglés, Olive Oil. Latín, Oleum Olivarum.

Terapéutica.-Ningún historiador antiguo nos habla de las propiedades terapéuticas que reconocieron nuestros mayores del olivo, si no son las que el empirismo de hoy da en sus aplicaciones del aceite extraído de la aceituna en las quemaduras de primer grado, y en los infinitos casos en que tiene lugar su empleo como vehículo en la medicina externa, en fricciones, aliado á otras substancias medicinales. Interiormente también tiene aplicaciones en el vómito que se desarrolla en Veracruz, estando ya aceptada su prescripción magistralmente. Se le conceden también propiedades emolieutes y laxantes, y está indicado en algunos casos de envenenamiento á la dosis de 15 á 30 gramos. Entra 
además en la composición de muchos emplastos y otras preparaciones farmacéuticas.

Las hojas del olivo que tienen un sabor agrio, varios autores extranjeros, entre ellos el $\mathrm{Dr}$. Biot, médico parisiense, las tienen indicadas como succedáneas de la quiña en el tratamiento de las fiebres intermitentes.

Posología.-Interiormente, 30 gramos.

Clasificación terapéutica.-El olivo está comprendido en la familia: 1a, Orgánicos Epihemapoieticos; clase 2a, Hydrocatexiopoieticos; género único, Liparoides de oliva.

José G. VÁzquez. 



